A paper presented at the Pacific Coast Meet-

ing of the American Institute of Electrical

Engineers, Los Angeles, A pril 25, 1911.

Copyright 1911. By A. I. E. E.

\title{
THE REFINING OF IRON AND STEEL IN INDUCTION TYPE FURNACES
}

BY C. F. ELWELL

Electrical Features

The furnaces for the refining of steel electrically, which have passed the experimental stage, may be divided into two distinct groups, viz., arc furnaces and induction furnaces.

To the former belong the Heroult, Stassano, Keller and Girod furnaces, and to the latter the Kjellin and Röchling-Rodenhauser furnaces. Of the former the Heroult furnace is perhaps the best known and most successful and as comparison always carries more weight than a description, it will be used as the representative of the arc furnaces. The electrical features may be divided up under several heads.

\section{Distribution of Heating Effect of the Current}

Arc Furnaces. In the Heroult furnace the current passes from one electrode through an arc to the slag, through the slag to the upper metal and thence through another arc to another electrode, and of the current which passes through the carbons only a small percentage passes through part of the metal. As the heating effect of the arc is far greater than any effect of the resistance of the charge, there must be large differences of temperature between different parts of the bath of metal even in spite of the great activity of the bath around the electrodes. This is especially the case with a deep bath of metal. It is for this reason that Girod employs a bottom electrode, thinking thus to have these differences of temperature less by passing all the current for the arcs through the bath. From figures given in Stahl 
and Eisen for a two-ton Girod furnace, it was computed that the resistance of the carbon electrode was 3800 times that of the bath of metal and so 3800 times more electrical energy was converted into heat in the carbon electrode than in the bath itself. From this it is seen that if the current in the bath of metal produces any considerable part of the heat of the furnace, there must be a large loss of energy in the carbon electrode. The only correction for this is to make the electrodes larger, and the working limit has already been reached. The fact is that the bath is very little heated by the passage of the current and almost all the heating in this type of furnace is done by the very localized heating of the arc. The matter of the losses of energy in the carbons will be taken up under the heading of efficiency.

Induction Furnaces. The principle of the induction furnace is already well known to you but in order to compare the Kjellin and Röchling-Rodenhauser types it will be well to repeat briefly the principle of operation and the type of construction of the Kjellin type. The furnace consists essentially of an iron core around one leg of which is wound a primary winding enclosed in a refractory case and usually cooled by means of forced draught. The annular hearth surrounds this primary coil and is separated from it by means of refractory material. This hearth contains the metal and acts as a secondary winding of one turn. The voltage induced in this turn is quite small so that the energy transformed from the primary coil results in a very large current in the secondary, which heats the metal and thus nearly all the electrical energy is converted into heat in the metal to be melted. The ring being of constant cross section, the heating is about uniform over the whole bath of metal. The Röchling-Rodenhauser furnace has a differently shaped hearth to the Kjellin furnace and a description would not be out of place at this juncture. The furnaces are constructed either for single- or three-phase current. In the former case there are two grooves and in the latter, three grooves. In both cases these grooves, which are similar to the grooves in the Kjellin furnace, open into a distinct open hearth. The cross section of the grooves is comparatively small and they form the secondary circuits in which the currents which heat the metal are induced. Lateral doors are provided so that the contents of the working chamber may be watched, slag drawn off or charge put in. The chief electrical difference between the Röchling-Rodenhauser 
and $\mathrm{Kjellin}$ furnace is that a distinct secondary winding is provided in the former and the current induced is led by means of heavy terminals to plates embedded in the refractory material of the furnace. This refractory material becomes an electrical conductor at the higher temperatures, and this enables an additional circuit to be formed, so that the currents induced in the secondary winding pass through the bath of metal, heating the bath still further. The current also serves to neutralize the great self-induction of the secondary and a better power factor is obtained. The point to be recognized here is that the heating is uniform and not localized as in the Heroult furnace.

\section{VARIATION OF LOAD ON SijpPly Mains}

Arc Furnace. The instability of an arc is well known and the load on a supply circuit, even with constant watching, varies very greatly. If the furnace has its own generator the regulation can be effected more simply but the best furnace is one which can be connected to regular three-phase supply mains. To do so with the Heroult furnace means motor-driven electrode regulators, etc., and even then the furnace is not a very desirable load.

Induction Furnaces. The changes in load on an induction furnace are always of the intentional kind and sudden changes of load are practically impossible with an induction furnace.

\section{Adaptability to Connection to Supply Mains}

In the question of power factor the Heroult furnace shows some advantage over the Kjellin furnace for in order to build a Kjellin furnace of eight-ton capacity and keep the power factor up to 0.6 or 0.7 it was necessary to lower the frequency to five periods per second. As a five-cycle generator costs more than twice as much as a 25 -cycle generator this is a serious question. But with the Röchling-Rodenhauser furnace the current in the second secondary winding can be used to neutralize the effect of self induction to such an extent that a seven-ton furnace may be operated with 25 cycles with a power factor of 0.6 while a threeton furnace on 25 cycles has a power factor of 0.8 . The smaller Röchling-Rodenhauser furnaces are operated from 50 cycles with power factors of 0.85 and 0.8 . In my opinion the most economical way to correct this evil is by using fixed condensers which cost only a small percentage of the cost of the furnace and the power factor may be made as high as desired. 


\section{Electrical EfFiciency}

Arc Furnaces. The before mentioned Girod furnace with but one electrode of $14 \mathrm{in} .(35.5 \mathrm{~cm}$.) diameter and a current of 6200 amperes at 60 volts showed a power loss of 10 per cent in the electrode alone. In the Heroult furnace the current is in general smaller but there are two electrodes in series and the result is about the same. Not only is energy lost in the electrodes by reason of their high resistance but a large amount is also lost by means of the water cooling of the jackets which is necessary because of their high conductivity for heat. The cost of maintenance of carbon electrodes is also considerable. Radiation loss is greater with the arc furnaces because a great deal of the heat of the arc is reflected to the roof which must be water cooled to last, and even then has to be renewed about every 14 days.

Induction Furnaces. Tests made on a 3.5 ton furnace at Volklingen have shown an electrical efficiency of 97 per cent which is a contrast to the 10 per cent lost in electrodes alone in arc furnaces. The electrode plates never wear out for they do not come in contact with the molten metal or slag and the portion of the lining which acts as a conductor has been found in practice to last longer than any other portion of the lining.

\section{Summary of Electrical Features}

$a$. Heating of metal bath is much more uniform in induction furnace.

$b$. The variation of load is much less with the induction furnace.

$c$. The adaptability to connection to existing power networks is in favor of the induction furnace.

$d$. The efficiency is in favor of the induction furnace.

\section{Metallurgical Features}

The earlier induction furnaces, i.e., those of the Kjellin type did not show many metallurgical advantages except that it was possible to treat much larger charges than with crucible methods. They were quite unsuited to working with slag because of the shape of the hearth and so only served to melt pure materials. The shape of the Röchling-Rodenhauser furnace is such that slags can readily be handled and refining carried on. At the same time it can be used for smelting work whenever necessary, and as much larger charges can be worked, a considerable saving is made in crucible steel working. 
The advantages of the electric furnace are:

1. On account of the convenient regulation of the temperature attainable the phosphorus can be removed until only a trace remains.

2. It is especially suitable for the most thorough desulphurization.

3. When the refining is complete, the charge can be left in the furnace as long as may be desired without change of composition.

At Trollhattan, Sweden, the furnace is started by means of a ring of metal. The cold materials are charged gradually until all are melted. Continuous operation is possible by leaving a portion of the molten metal in the furnace after cach teeming.

At Volklingen, Germany, the furnaces are supplied with molten metal from basic Bessemer converters which contains about 0.08 per cent $S$ and 0.08 per cent P. The extent of the dephosphorization and desulphurization depends on what the steel is wanted for.

An oxidizing slag is formed from lime and millscale or ore, which is removed as far as possible when dephosphorization is complete. The re-carburization takes place and a slag free from iron is formed for desulphurization. A typical slag for desulphurization has a well-known white appearance and falls to a white powder on exposure to the air. When the slag has this property, the charge may be left as long as desired in the furnace. The furnaces are entirely emptied after each charge as the molten converter steel allows the load to be readily brought to a satisfactory figure.

When not working, about one third of the normal energy will keep the furnace hot. The seven-ton furnace at Volklingen has been 30 hours without taking any current and was heated up again with normal energy consumption. Within half an hour the metal began to glow and regained its normal temperature after four hours and the charge was finished up in the regular way. At the works at Volklingen no work is done on Sunday but there is no difficulty in starting up the furnaces with unfinished charges from the previous Saturday.

The natural circulation which takes place in induction furnaces serves to thoroughly mix the charge and the management of the Poldihütte, Austria, made a test in which seven samples. were taken from six different places in the furnace and the analysis of these samples is shown in the following table: 


\begin{tabular}{|c|c|c|c|c|c|c|}
\hline & $\begin{array}{l}\text { Carbon } \\
\text { Per cent }\end{array}$ & $\begin{array}{c}\text { M anganese } \\
\text { Per cent }\end{array}$ & $\begin{array}{l}\text { Silicon } \\
\text { l'er cent }\end{array}$ & $\begin{array}{c}\text { Phosphorus } \\
\text { Per cent }\end{array}$ & $\begin{array}{l}\text { Sulphur } \\
\text { Per cent }\end{array}$ & $\begin{array}{c}\text { Chromium } \\
\text { Per cent }\end{array}$ \\
\hline 1 & 0.81 & 027 & 0.335 & 0.031 & 0.007 & 1.00 \\
\hline 2 & 0.77 & 0 & 0.340 & 0.030 & 0.008 & $\begin{array}{l}1.00 \\
1.01\end{array}$ \\
\hline 3 & 0.85 & 0 & .0 .345 & 0.029 & 0.007 & $\begin{array}{l}1.00 \\
1.01\end{array}$ \\
\hline 4 & 0.82 & $\begin{array}{lll}0 & 27\end{array}$ & 0.335 & 0.030 & 0.009 & $\begin{array}{l}0.98 \\
0.99\end{array}$ \\
\hline 5 & 0.78 & 0.25 & 0.335 & 0.030 & 0.009 & $\begin{array}{l}0.99 \\
0.96\end{array}$ \\
\hline 6 & 0.78 & 0.27 & 0.419 & 0.031 & 0.010 & 0.99 \\
\hline 7 & 0.79 & 028 & 0.326 & 0.030 & 0.009 & 0.98 \\
\hline
\end{tabular}

The furnace was teemed 37 minutes later and a sample cast out of the ladle gave the following analysis:

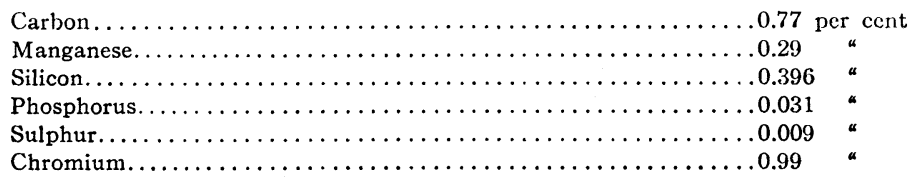

That the Röchling-Rodenhauser furnace is no longer an experiment is shown by the fact that the 3.5-ton furnace was worked for a whole year producing steel for rails, and more than 5,000 tons have been sold. The eight-ton furnace has been running since November, 1908, an average of 14 days to a lining and 1,200 tons of rails to a lining. The management contemplates the building of a 16-ton furnace as the next step.

At Dommeldingen the two-ton furnace is used to refine crude pig iron.

\begin{tabular}{|c|c|c|}
\hline & $\begin{array}{c}\text { Analysis of } \\
\text { charge }\end{array}$ & $\begin{array}{l}\text { Analysis of } \\
\text { cast }\end{array}$ \\
\hline 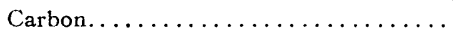 & 4.0 per cent & 0.5 per cent \\
\hline 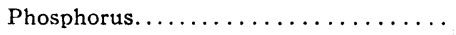 & $1.8 \quad$ & $0.025 \quad \alpha$ \\
\hline 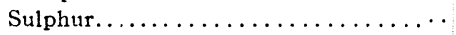 & 0.2 & 0.03 \\
\hline 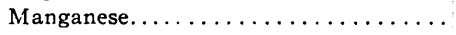 & 0.0 & 0.76 \\
\hline 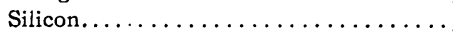 & 1.05 & 0.056 \\
\hline
\end{tabular}

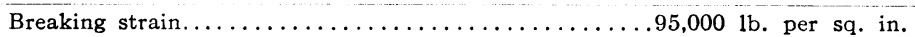

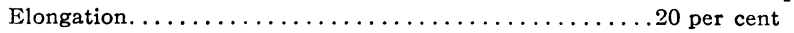

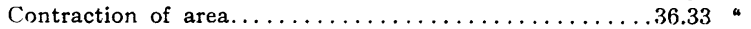

Duration of conversion.................. 


\section{Summary of Metallurgical Features}

1. Having no electrodes, facilities are provided for heating the bath without introducing impurities and the charge may be left indefinitely in the Röchling-Rodenhauser furnace without change.

2. Having a large open hearth, (in the 1.5-ton furnace it is 60 by 26 in. or 1.52 by $0.65 \mathrm{~m}$.) with doors it is possible to do any class of refining in the Röchling-Rodenhauser furnace much the same as in the open hearth furnace.

3. When the hearth doors are closed the Röchling-Rodenhauser furnace is air-tight and may be left for long periods without great loss of heat, making intermittent working possible.

4. The natural gentle movement of the charge allows of complete mixing of the ingredients of the charge, and is not sufficient to attack the lining.

\section{Costs}

Royalty. The German users of the induction furnace pay $\$ 0.65$ per ton for rail steel and $\$ 1.50$ per ton for crucible quality steel. This is for small daily production. For 1000 tons daily the royalty is placed at $\$ 0.36$ per ton for rail steel and for 1200 tons daily it is $\$ 0.50$ for crucible quality steel.

Energy Required. A great many figures have been given out most of which were for small furnaces and special runs. The plants at Trollhattan and Volklingen being in commercial operation supply the most reliable figures obtainable.

Cold Pig and Scrap. With cold materials, refining, etc., to crucible quality steel is done with 600 to $900 \mathrm{kw}-\mathrm{hr}$. per ton according to the size of the furnace.

IIot Pig and Scrap. With hot pig iron and cold scrap crucible quality steel is obtained with 300 to $700 \mathrm{kw}-\mathrm{hr}$. per ton according to the proportions of the two ingredients and the size of the furnace.

Hot Metal from the Converter. Converter material with an analysis of $\mathrm{P}, 0.08$ per cent; $\mathrm{S}, 0.08$ per cent; $\mathrm{Mn}, 0.5$ per cent; $\mathrm{C}, 0.1$ per cent is refined to steel for rails with an analysis of $\mathrm{P}$, 0.05 per cent; S, 0.04 per cent; $\mathrm{Mn}, 0.85$ per cent; $\mathrm{C}, 0.5$ per cent with $100 \mathrm{kw}$-hr. per ton in a seven ton furnace. Same material is refined to high quality steel showing only traces of $\mathrm{P}$ and $\mathrm{S} ; \mathrm{Mn}, 0.2$ per cent; C, 0.5 per cent with $250 \mathrm{kw}-\mathrm{hr}$. per ton.

IIot Metal from Open Hearth Furnace. Material from open hearth furnace, already dephosphorized and desulphurized and 
containing 1.22 per cent $\mathrm{C}$; Mn, 0.38 per cent; $\mathrm{Si}, 0.21$ per cent to high quality steel with 200 to $250 \mathrm{kw}$-hr. per ton.

Cost of Production. (1) For a 1.5-ton furnace melting scrap and refining to pour best steel for steel castings. Furnace of the three-phase, tilting type. 50 cycles, $210 \mathrm{kw}$. and power factor 0.80 .

Interest Charges. Cost with all accessories about $\$ 9,000$. With 10 per cent for interest charges gives $\$ 900$ annually. Using 290 working days in a year and six charges, 3 to 3.5 hours each, daily and $1500 \mathrm{lb}$. to a charge gives 4.2 tons daily and 1,220 tons yearly. This is equivalent to about 21 hours working. Cost per ton for interest, $\$ 0.74$.

Labor. Two men can attend to this furnace with ease, as the electrical part requires no special attention. The melter adjusts the temperature and watches the metallurgical process. The helper sees to the fan and charging etc. Allowing two shifts and $\$ 5.50$ per shift or $\$ 11$ daily gives a labor cost of $\$ 2.62$ per ton of steel.

Lining. Relining may be done every 8 or 14 days. It takes three tons of magnesite and 0.36 ton of tar to completely reline the furnace. The relining is done with half new material and half old. For getting out the old lining, mixing material and putting in the new, four men are allowed 16 hours. Cost of lining per ton of steel, on an average, $\$ 1.50$.

If lined with dolomite, which is cheaper, and every 14 days then lining cost allowing one third material recovered is $\$ 1.00$ per ton of steel.

Keeping Warm. When the furnace is not used for several hours during the night, it must be kept warm, for which about a third of the working amount of energy is necessary. In this way if normal energy is $200 \mathrm{kw}$. then about $200 \mathrm{kw}-\mathrm{hr}$. will be necessary to keep the furnace warm over the three-hour period of rest. For six working days this is necessary five times and 1000 kw-hr. must be charged up to heating.

Cost of keeping furnace warm at $\$ 20.00$ per $\mathrm{kw}-\mathrm{yr}$. is $\$ 0.09$ per ton of steel.

Cooling of Transformer. The blower takes a 2.5-h.p. motor or $1.8 \mathrm{kw}$. and for 24 hours $=43 \mathrm{kw}-\mathrm{hr}$.

Cost of cooling transformer per ton of steel, $\$ 0.02$.

Energy Consumption. From cold materials about 850 to $900 \mathrm{kw}-\mathrm{hr}$. are necessary, in this size furnace. Taking larger figure the cost of energy per ton is $\$ 2.06$.

Royalty. In the United States, on the basis of a plant of 50 tons daily the royalty would be about 50 cents per ton. 
SUMMARY OF COST

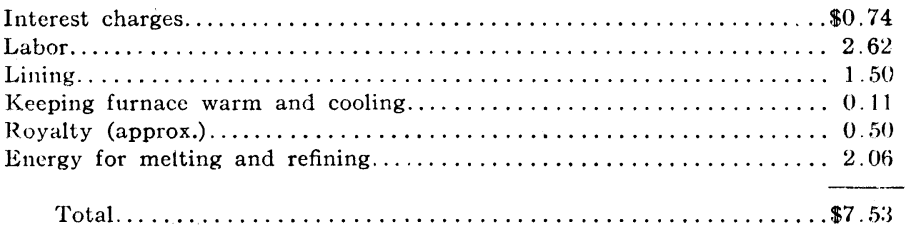

The figure $\$ 7.53$ is the working cost which must be added to the cost of the materials in order to find the cost of crucible quality steel from scrap. The above figure would be more reasonable with larger furnaces.

Cost of Production. (2) For a two-ton, 300 kw., three phase tilting furnace.-Molten converter steel to quality steel for castings.

Cost with all accessories about $\$ 12,500$. With 10 per cent for interest charges gives $\$ 1250$ per annum. Allowing 250 working days in the year and 16 tons per day gives 4,000 tons per annum or $\$ 0.31$ per ton of steel.

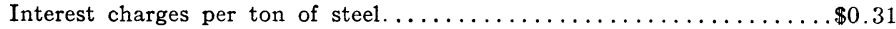

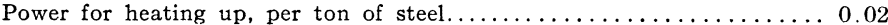

Power for refining, allowing upper figure of $300 \mathrm{kw}-\mathrm{hr}$. at $\$ 20$ per $\mathrm{kw}-\mathrm{yr} . .0 .68$

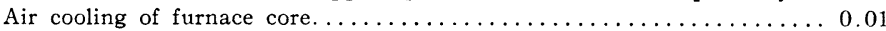

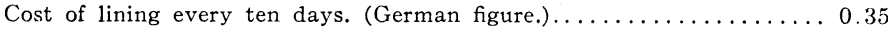

Wages allowing $\$ 16$ per day...............................

Royalty on basis of 50 tons daily ........................ 0.50

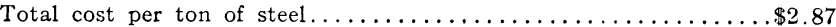

This figure would give a good idea of the cost of converting molten pig iron into steel, exclusive of the ferro alloys.

Cost of Production. (3) For a five ton, 550 kw., three phase tilting furnace.-Molten converter steel to crucible quality steel.

Cost with all accessories about $\$ 22,000$. With 10 per cent for interest charges gives $\$ 2,200$ per annum. Reckoning 250 working days in the year, each one with eight heats of five tons, the yearly production would be 10,000 tons, or $\$ 0.22$ per ton for interest charges.

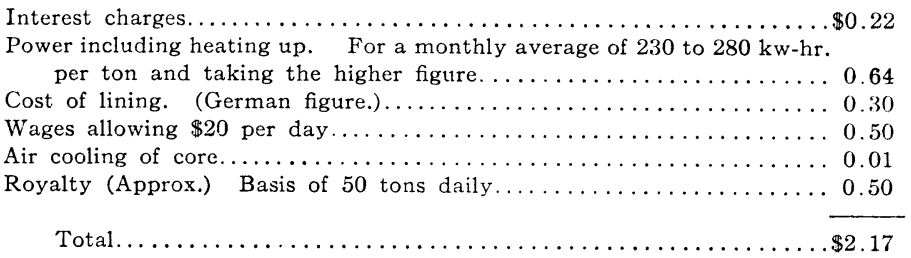

Cost of Production. (4) For a seven ton, $750 \mathrm{kw}$., three-phase, 25-cycle, 0.6-power factor tilting type furnace.-Converting molten converter steel into high grade rails. For analysis see page 626. 
Cost with all accessories $\$ 27,000$. Interest charges at 10 per cent gives $\$ 2700$ per annum. Allowing 100 tons daily (the makers claim a production of 140 tons) and 250 working days in the year gives a yearly production of 25,000 tons of rail steel and interest charges per ton of steel $=\$ 0.11$.

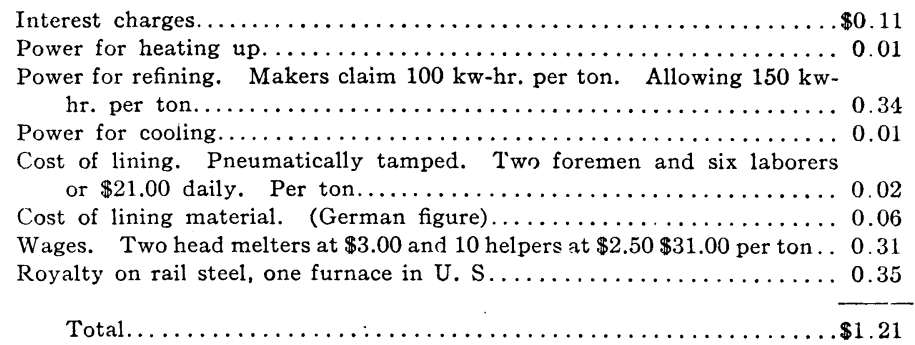

This is the conversion cost which added to the value of the pig and ferro alloys, etc., gives the cost of steel for rails. The Prussian Railways paid $\$ 10$ extra per ton for rails made in this furnace and were well pleased with the product.

Cost of Production. (5) For a seven-ton, 750-kw., three-phase, 25-cycle, 0.6-power factor, tilting type furnace.-Molten converter steel to highest quality steel. For analysis see page 626 .

This furnace will produce about half the steel of this quality as when working on rail steel or 50 tons daily.

The cost per ton under these conditions is about $\$ 2.00$ per ton including royalty.

\section{Summary of Costs of Production Exclusive of Materials}

1.5-ton furnace melting scrap and refining to pour high grade steel for

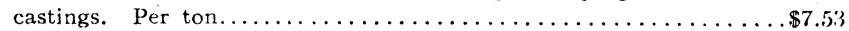

2-ton furnace refining molten converter steel to high grade stecl. Per ton . 2.87

5-ton furnace refining molten converter steel to high grade steel. Per ton. . 2.17

7 -ton furnace refining molten converter steel to high grade steel, Per ton. . 2.0y

7-ton furnace refining molten converter steel to high grade rails. Per ton. 1.21 